\title{
Re-evaluating NADPH-diaphorase histochemistry as an indicator of nitric oxide synthase: an examination of the olfactory system of coho salmon (Oncorhynchus kisutch)
}

\author{
Sean C. Lema , Gabrielle A. Nevitt
}

\begin{abstract}
The NADPH-diaphorase (NADPH-d) histochemical technique is commonly used to localize the nitric oxide (NO)-producing enzyme NO synthase (NOS) in neural tissues. In the olfactory tissues of vertebrates, however, NADPH-d staining can be present without the detection of NOS by other methods. We used pharmacological controls to determine whether NADPH-d staining was indicative of NOS in olfactory tissues from coho salmon (Oncorhynchus kisutch). We also compared NADPH-d staining with immunoreactivity to NOS. NADPH-d staining localized to the olfactory epithelium and to the glomerular layer of the olfactory bulb. Two NOS inhibitors, L- $N$-nitroarginine and L- $N$-methyl-L-arginine, failed to block this staining, but the less specific flavin-binder, diphenylene iodonium chloride, decreased or eliminated NADPH-d staining in all olfactory tissues. Immunoreactivity to NOS was present in short axon cells of the bulb, but was absent from the epithelium. Our findings show that NADPH-d staining was not representative of NOS in the olfactory tissues of salmon.
\end{abstract}

Keywords: NADPH-diaphorase; Nitric oxide synthase inhibition; Olfaction; Salmon; Oncorhynchus kisutch; Nitroarginine

The gaseous signaling molecule nitric oxide (NO) plays multiple roles in olfaction. In addition to its role during the development and regeneration of olfactory receptor neurons $[1,15]$, NO has been implicated to function in the formation of olfactory memories at the level of the olfactory bulb [10]. The picture that is emerging suggests that NO functions as an intercellular second messenger in the olfactory system by diffusing across cell membranes and activating guanylyl cyclase.

The presence of NO in olfactory tissues, however, is not without controversy. In vertebrates, there are conflicting reports concerning the presence of the NO-generating enzyme NO synthase (NOS) in the peripheral olfactory system. Many studies have reported the presence of NADPH-diaphorase (NADPH-d) histochemical staining in the olfactory epithelium (for example see Refs. [5,15,18]). Since the distribution of NADPH-d staining has been shown to correspond to the distribution of NOS-ir in the rat brain [4], NADPH-d staining in olfactory tissues is often assumed to be an indicator of NOS. Studies employing other meth- ods, however, have been unable to find evidence for NOS in the olfactory epithelium. Verma et al. [16] examined olfactory neuronal cultures from neonatal rats with catalytic assay, protein immunoblot, and RNA blot, but found no evidence for the expression of NOS. Similarly, Roskams et al. [15] found that immunoreactivity to NOS (NOS-ir) was only present in the olfactory epithelium of rats during embryonic development, and was not present in adults.

In light of this contradictory evidence, Dellacorte et al. [5] examined the specificity of NADPH-d staining to NOS in the olfactory tissues of adult channel catfish (Ictalurus punctatus) and rats. The authors showed that the NOS-selective inhibitors, L- $N$-nitroarginine (L-NNA) and L- $N$-methylL-arginine (L-NMA), eliminated or reduced NADPH-d staining in the olfactory epithelium and bulb of both species. Dellacorte et al. [5] also demonstrated the conversion of $\left[{ }^{3} \mathrm{H}\right]$-L-arginine to $\left[{ }^{3} \mathrm{H}\right]-\mathrm{L}$-citrulline, the reaction mediated by NOS, in olfactory cilia isolated from the rat and catfish. This evidence led the authors to conclude that NADPH-d staining was due to NOS in the epithelium of these vertebrates. It remains unclear, however, how NADPH-d staining could be due to NOS when other techniques including 
immunohistochemistry [15] and RNA blot [16] provided no evidence for NOS in the same tissues.

In this study, we examined NADPH-d staining as a possible indicator of NOS in the olfactory tissues from coho salmon (Oncorhynchus kisutch). Hatchery-reared salmon exposed to odors during a sensitive period of development called the parr-smolt transformation period imprint to these odors and home to them during the spawning migration [6]. The parr-smolt transformation is also a period when significant structural changes in the olfactory system have been reported [9], including enhanced cellular proliferation in the olfactory receptor epithelium [17]. Since NO has been shown to play a role in olfactory learning [10] and in the development of olfactory receptor neurons [15] in other species, NO may be involved in olfactory imprinting in salmon.

The purpose of our study was to determine if NADPH-d staining and NOS were present in the olfactory system of salmon during the parr-smolt transformation. We controlled for enzymes other than NOS that can catalyze the NADPH-d reaction in two ways: (1) with two selective antagonists of NOS, L-NNA and L-NMA; and (2) with the less specific flavin-binder, diphenylene iodonium chloride (DPI). The compounds L-NNA and L-NMA both inhibit the NOS enzyme [7,12] and eliminate NADPH-d staining due to NOS [2]. If NADPH-d staining is mediated by NOS, then these NOS antagonists will block the NADPH-d staining. In contrast, DPI will inhibit NOS and all other enzymes that catalyze the NADPH-d reaction via a flavin mechanism [2]. We also examined olfactory tissues using an antibody to NOS to determine if NOS-ir co-localized with the NADPH-d reaction products.

Coho salmon were obtained from Iron Gate Fish Hatchery on the Klamath River, California, and maintained in fresh water at $10-12^{\circ} \mathrm{C}$ at the Bodega Marine Laboratory and the Center for Aquatic Biology of the University of California, Davis. Fish were examined during the parr-smolt transformation, an established period for behavioral and physiological imprinting [6]. We previously established this period as a time of enhanced cell proliferation in the olfactory epithelium in this population of salmon [17].

Twelve fish (weight: 27.8-57.5 g; standard length: 127$160 \mathrm{~mm}$ ) were anesthetized with MS222 and perfused transcardially with chilled heparinized phosphate buffered saline (0.1 M PBS; $\mathrm{pH} 7.4$ ) and then 4\% paraformaldehyde in PBS. Fixation with paraformaldehyde has been shown to eliminate most NADPH-d staining that is not due to NOS [13]. Following perfusion, the olfactory rosettes and brains were removed and post-fixed in $4 \%$ paraformaldehyde with $30 \%$ sucrose in PBS, and emersed in $30 \%$ sucrose-PBS at $4^{\circ} \mathrm{C}$ for $18-20 \mathrm{~h}$. Tissue was embedded, frozen, and sectioned at $-19^{\circ} \mathrm{C}$. Olfactory rosettes $(20 \mu \mathrm{m})$ and brains $(30 \mu \mathrm{m})$ were thawmounted on gelatin-coated slides, and stored at $-20^{\circ} \mathrm{C}$.

For NADPH-d histochemistry, slides were incubated for 2-4 $\mathrm{h}$ at room temperature in the dark in Tris- $\mathrm{HCl}$ buffer (0.1 M; pH 8.0) with four treatments used on consecutive tissue sections: (1) L-NNA (5 mM; Sigma); (2) L-NMA (5 mM; Sigma); (3) DPI (1 mM; Sigma); and (4) no inhibitor. Following incubation, we immersed olfactory rosettes for up to $90 \mathrm{~min}$ and brains for up to $120 \mathrm{~min}$ in a NADPH-d staining solution at $37^{\circ} \mathrm{C}$ in the dark $(0.9 \mathrm{mM}$ nitro blue tetrazolium, Fisher; $0.45 \mathrm{mM} \beta \mathrm{NADPH}$, Sigma; 0.3\% Triton X-100 in Tris-HCl buffer). Removal of $\beta$ NADPH from the staining solution prevented all diaphorase staining. We stopped the NADPH-d reaction by rinsing tissues in phosphate buffer.

For NOS immunohistochemistry, slides were incubated in PBS with $0.3 \%$ Triton X-100 (PBST; pH 7.4) and 5\% normal goat serum for $2 \mathrm{~h}$. Slides were then incubated at $4{ }^{\circ} \mathrm{C}$ overnight in PBST with 5\% goat serum and anti-NOS antiserum (polyclonal rabbit 'universal' anti-NOS antibody, uNOS, Affinity BioReagents Inc.) at 1:100 for brains and 1:200 for olfactory rosettes. The secondary antibody was visualized using an avidin-biotin-peroxidase secondary complex (Rabbit IgG; Vector Laboratories) and diaminobenzidine with nickel enhancement. Alternate control sections were run without primary antibody on every fish. To evaluate whether the 'universal' anti-NOS antibody binds NOS in tissues from coho salmon, we examined NOS-ir staining in the brain. NADPH-d staining co-localized with NOS-ir in the Purkinje cells of the cerebellum (result not shown). A similar co-localization to Purkinje cells has been reported in Atlantic salmon, Salmo salar [8], suggesting that the 'universal' anti-NOS antibody bound NOS in neural tissues from coho salmon.

We detected NADPH-d staining in both the olfactory epithelium and bulb of salmon. In the epithelium, staining localized to the olfactory nerve bundles and the cytoplasm of four morphologically distinct cell types: olfactory receptor cells, support cells, secretory goblet cells, and basal cells. Olfactory receptor cells stained for NADPH-d in both the dendrites and axons but not in the nucleus (Fig. 1). Even though we noted staining in many distinct cell types, stained cells were sporadically distributed throughout the epithelium and we saw no clear pattern to their distribution. The NADPH-d staining also localized to unidentified globular structures at the mucosal surface of the epithelium (asterisks, Fig. 1) as well as to the glomerular layer of the olfactory bulb. Glomerular staining was diffuse and could not be attributed to any particular cell type. Pre-incubation of tissue with either of the two NOS inhibitors, L-NNA or LNMA, failed to block NADPH-d staining in the salmon olfactory bulb or epithelium (Fig. 2B,E). Pre-incubation of tissues in the flavin-binder DPI, however, decreased or eliminated NADPH-d staining in all olfactory tissues (Fig. $2 \mathrm{C}, \mathrm{F})$, suggesting that an enzyme with a flavin mechanism catalyzed the NADPH-d reaction.

We did not find evidence for NOS-ir in the olfactory epithelium of any fish. In contrast, NOS-ir was detected in short axon cells of olfactory bulb from two of the 12 fish. These cells showed cytoplasmic staining of the cell body and dendrite (Fig. 3). NADPH-d staining was not present in 


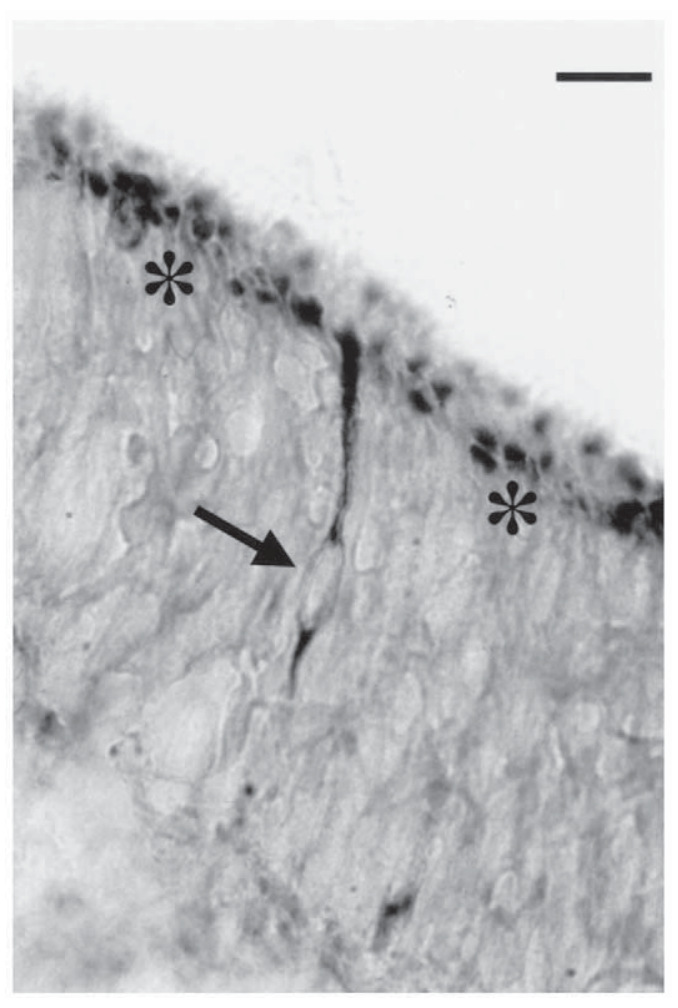

Fig. 1. NADPH-d staining in olfactory receptor neurons. NADPHd stained olfactory receptor neurons that were characterized by a long dendrite extending to the mucosal surface and an unstained nucleus (arrow). Globular structures located at the mucosal surface (asterisks) stained positively for NADPH-d throughout the epithelium. Scale bar: $10 \mu \mathrm{m}$.

these cells, and did not co-localize with NOS-ir in the bulb of these fish.

The distribution of NADPH-d staining in the epithelium and bulb of coho salmon is consistent with results from previous studies examining NADPH-d staining in the olfactory system (mammals: [5,11]; amphibians: [14]; and fish: $[5,8,18])$. Our results, however, suggest that the NADPH-d staining we observed in the olfactory system was not due to NOS. First, we found that the two NOS-specific inhibitors, L-NNA and L-NMA, failed to block the NADPH-d staining. Second, NOS-ir was not indicated in alternate sections. Taken together, these results are consistent with the idea that NADPH-d staining is not specific for the detection of NOS in the olfactory system. Our results coincide with studies from other laboratories which concluded that NOS-ir was not present in the peripheral olfactory system of vertebrates past the embryonic or larval stages of development (e.g. [1,15]).

In contrast to our results in salmon, Dellacorte et al. [5] showed that the same NOS-selective inhibitors L-NNA and L-NMA prevented NADPH-d staining in the olfactory epithelium and bulb of adult rats and catfish. There are several possible explanations for the discrepancy between our results and those of Dellacorte et al. [5]. First, Dellacorte et al. [5] hypothesize that NADPH-d staining in the olfactory

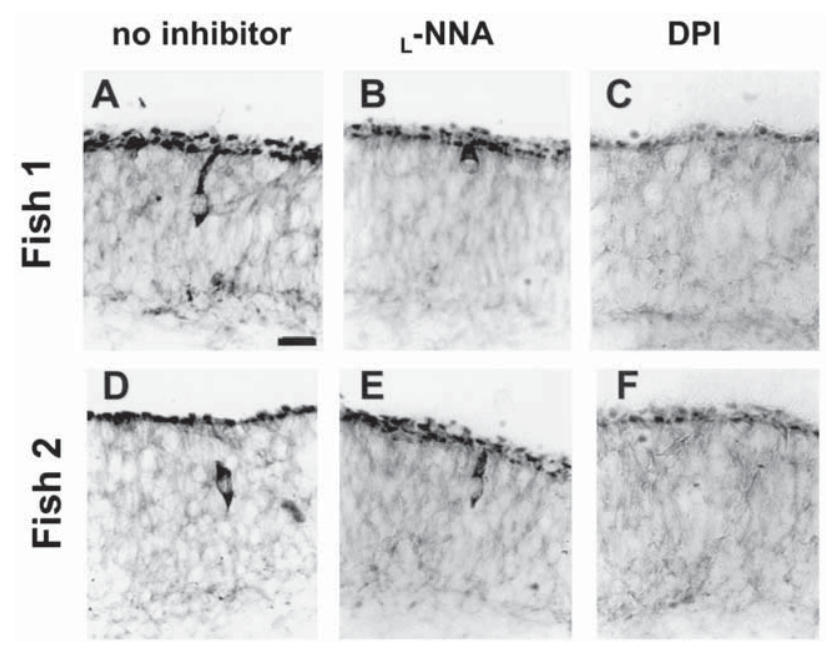

Fig. 2. NOS inhibitors failed to block NADPH-d in the olfactory epithelium. NADPH-d staining without NOS inhibitors $(A, D)$. Incubation of tissue in the NOS inhibitor L-NNA failed to block NADPH-d staining (B,E), but DPI blocked NADPH-d staining throughout the epithelium (C,F). Series (A-C) (Fish 1) and (D-F) (Fish 2) were taken from serial sections of the same lamellae from two fish. Due to the small number of stained cells, $(A, B$, $D, E)$ were selected specifically to show NADPH-d stained cells. No stained cells were present in the epithelium following incubation with DPI (C,F). Scale bar: $10 \mu \mathrm{m}$.

system may be catalyzed by an immunologically distinct, and possibly unrecognized, isoform of NOS that is not detected by antibodies to the neuronal isoform of NOS. Although our results do not exclude this possibility, we do not consider this to be the most likely explanation for the differing results. Our histochemical protocol used the same NOS inhibitors as Dellacorte et al. [5] and would have blocked the NADPH-d staining, even if the NADPH-d reaction was catalyzed by a novel isoform of NOS. A second explanation for the discordant results of Dellacorte et al. [5] and the present study may

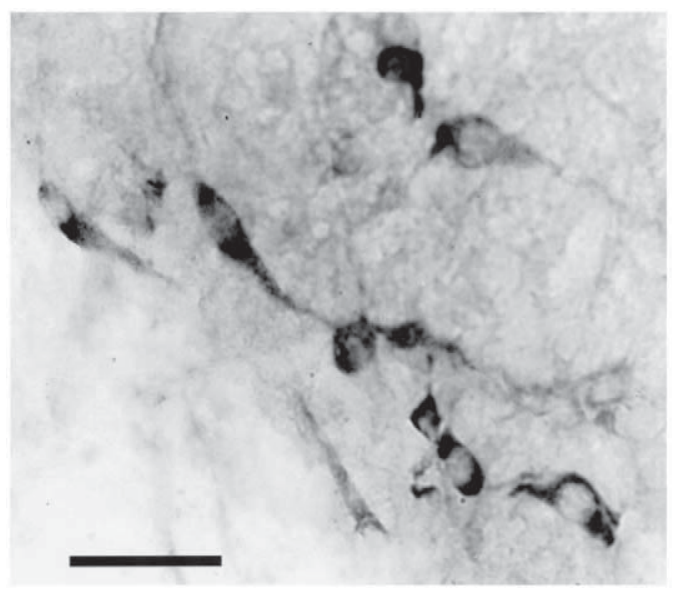

Fig. 3. Evidence for NOS-ir in short axon cells of the olfactory bulb. NOS-ir was present in short axon cells in the olfactory bulb of two of twelve fish examined. The cytoplasm surrounding the unstained nucleus and dendrites both stained with NOS-ir. Scale bar: $20 \mu \mathrm{m}$. 
be that the NADPH-d reaction was catalyzed by enzymes other than NOS. In general, the NADPH-d reaction is catalyzed by at least eight enzymes [3], many of which function through a flavin-mechanism. This flavin mechanism can be blocked by DPI. In our study, DPI inhibited the NADPH-d staining, suggesting that the enzyme which catalyzed this reaction may be included in this group of enzymes containing flavin binding sites. The results of Dellacorte et al. [5] are not entirely contrary to this explanation. Dellacorte et al. [5] found that the NOS inhibitors L-NNA and L-NMA eliminated NADPH-d staining in the rat olfactory epithelium and accessory olfactory bulb but only reduced staining in the glomeruli of the main olfactory bulb, suggesting that enzymes other than NOS could have been responsible for part of the NADPH-d staining in the olfactory bulb of the rat.

In the present study we found no evidence for the expression of NOS in the olfactory epithelium of salmon. Further, our results demonstrate that proper controls are necessary to equate NADPH-d staining with the presence of NOS in the peripheral olfactory system. The NADPH-d technique, however, may still serve as an accurate histochemical marker for NOS in other neural tissues including the central nervous system (e.g. [4]). While the use of NADPH-d staining as an indicator of NOS in tissues other than the olfactory system was not examined in the present study, our results caution against generalizing the specificity of NADPH-d staining for NOS across tissues. Many previous studies have attributed NADPH-d staining in olfactory tissues to NOS without conducting appropriate controls for the NADPH-d reaction. Such reported distributions of NOS in the olfactory system may be inaccurate, so care should be taken in interpreting their results.

Thanks to Barbara Zielinski for guidance with the NADPH-d technique, and Andy Dittman and Kate Clark for comments on the manuscript. A Howard Hughes Medical Institute Undergraduate Research Fellowship and a President's Undergraduate Fellowship to S.C.L, and The Whitehall Foundation (J96P15) and an NIH First Award (PHS DCO3174) to G.A.N helped support this research.

[1] Arnhold, S., Anderssen, C., Bloch, W., Mai, J.K. and Addicks, K., NO synthase-II is transiently expressed in embryonic mouse olfactory receptor neurons, Neurosci. Lett., 229 (1997) 165-168.

[2] Blotter, D. and Baumgarten, H.G., L-NNA inhibits the histochemical NADPH-d reaction in rat spinal cord neurons, Histochemistry, 103 (1995) 379-385.

[3] Blotter, D., Grozdanovic, Z. and Gossrau, R., Histochemistry of nitric oxide synthase in the nervous system, Histochem. J., 27 (1995) 758-811.

[4] Dawson, T.M., Bredt, D.S., Fotuhi, M., Hwang, P.M. and Snyder, S.H., Nitric oxide synthase and neuronal NADPH diaphorase are identical in brain and peripheral tissues, Proc. Natl. Acad. Sci. USA, 88 (1991) 7797-7801.

[5] Dellacorte, C., Kalinoski, D.L., Huque, T., Wysocki, L. and Restrepo, D., NADPH diaphorase staining suggests localization of nitric oxide synthase within mature vertebrate olfactory neurons, Neuroscience, 66 (1995) 215-225.

[6] Dittman, A.H., Quinn, T.P. and Nevitt, G.A., Timing of imprinting to natural and artificial odors by coho salmon (Oncorhynchus kisutch), Can. J. Fish. Aquat. Sci., 53 (1996) 434-442.

[7] Furfine, E.S., Harmon, M.F., Paith, J.E. and Garvey, E.P., Selective inhibition of constitutive nitric oxide synthase by L-N ${ }^{G}$-nitroarginine, Biochemistry, 32 (1993) 8512-8517.

[8] Holmqvist, B.I., Östholm, T., Alm, P. and Ekström, P., Nitric oxide synthase in the brain of a teleost, Neurosci. Lett., 171 (1994) 205-208.

[9] Jarrard, H.E., Postembryonic changes in the structure of the olfactory bulb of the chinook salmon (Oncorhynchus tshawytscha) across its life history, Brain Behav. Evol., 49 (1997) 249-260.

[10] Kendrick, K.M., Guevara-Guzman, R., Zorrilla, J., Hinton, M.R., Broad, K.D., Mimmack, M. and Ohkura, S., Formation of olfactory memories mediated by nitric oxide, Nature, 388 (1997) 670-674.

[11] Kishimoto, J., Keverne, E.B., Hardwick, J. and Emerson, P.C., Localization of nitric oxide synthase in the mouse olfactory and vomeronasal system, Eur. J. Neurosci., 5 (1993) 1684-1694.

[12] Klatt, P., Schmidt, K., Brunner, F. and Mayer, B., Inhibitors of brain nitric oxide synthase, J. Biol. Chem., 269 (1994) 1674-1680.

[13] Matsumoto, T., Nakane, M., Pollock, J.S., Kuk, J.E. and Förstermann, U., A correlation between soluble brain nitric oxide synthase and NADPH-diaphorase activity is seen only after exposure of the tissue to fixative, Neurosci. Lett., 155 (1993) 61-64.

[14] Porteros, A., Arévalo, R., Crespo, C., Briñón, J.G., Weruaga, E., Aijón, J. and Alonso, J.R., Nitric oxide synthase activity in the olfactory bulb of anuran and urodele amphibians, Brain Res., 724 (1996) 67-72.

[15] Roskams, A.J., Bredt, D.S., Dawson, T.M. and Ronnett, G.V., Nitric oxide mediates the formation of synaptic connections in developing and regenerating olfactory receptor neurons, Neuron, 13 (1994) 289-299.

[16] Verma, A., Hirsch, D.J., Glatt, C.E., Ronnett, G.V. and Snyder, S.H., Carbon monoxide: a putative neural messenger, Science, 259 (1993) 381-384.

[17] Watters, J.V., Wrights, D. and Nevitt, G.A., Testing a new model for olfactory imprinting in coho salmon (Oncorhynchus kisutch), Chem. Senses, 23 (1998) 636.

[18] Zielinski, B.S., Osahan, J.K., Hara, T.J., Hosseini, M. and Wong, E., Nitric oxide synthase in the olfactory mucosa of the larval sea lamprey (Petromyzon marinus), J. Comp. Neurol., 365 (1996) 18-26. 